\title{
ON THE SOCIAL COSTS OF MODERNIZATION: Social Disintregation, Atomie/Anomie and Social Development
}

\author{
JOHAN GALTUNG \\ Senior Advisor, UNRISD, in preparation for the WORLD SUMMIT FOR SOCIAL \\ DEVELOPMENT, Copenhagen, March 11-12 1995. \\ Professor of Peace Studies; Universitaet Witten/Herdecke, University of Hawai'i, \\ European Peace University, Universidad de Alicante, TRANSCEND Member, \\ International Scientific Board, Swiss Academy for Development.
}

Geneva, January 1995

Honolulu, February 1995

\section{SUMMARY}

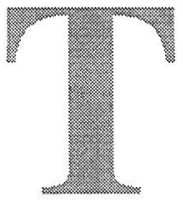

he modernization project launched by the West two centuries ago, was based on three pillars: State-logic, $\mathrm{Ca}$ pital-logic and Ratio-logic; formulated in part by Montesquieu (France), Smith (Britain) and Kant (Germany). The logic of the State implied centralization of coercive power, tempered by democracy. The logic of Capital implied market forces for economic power, tempered by anti-monopoly clauses. The logic of Ratio implied secularization for normative power. The result was spectacular, with bureaucracies, corporations and universities being major carriers of the triple logic, with ring-effects all over.

All of this was colored by Western deep culture, with its focus on dominion over nature; a sharp body-spirit division mirrored in a social division between merchants catering to the body, clergy catering to the spirit and aristocracy protecting both but also having ultimate power (whence grew Capital, Ratio and the State); social atomism (individualism) with hierarchic organization of people; epistemological atomism and hierarchic organization of ideas (deductive systems); a very dichotomous world image; and a religion/ideology seen as singularist (the only Truth) and universalist (valid for the whole world). Abroad "modernization" became Westernization, and with the recent predominance of Economic Man became identified with economic growth as the key program for the whole world the last decades. 
Much naivete is needed to believe that this can happen without enormous social costs, whether in the form of the slow but thorough modernization of the West or the more superficial, but quicker Westernization of the rest. The costs are there.

The focus of the paper is on two basic types of costs: destructuration, or atomie, weakening of direct interaction, deculturation, or anomie, weakening of compelling norms.

The result is "monadization" (Leibniz) of society into mutually isolated monads steered by egocentric cost-benefits.

This is seen as a process "from nomadism to monadism", from dense relatively horizontal structures with norms of compassion for the ingroup, gradually weakened as vertical structures with norms of submission grow stronger and more world-encompassing until the latter also weakens through automation/information. The result is an enormous increase in violence at all levels of social organization, the atomie/anomie syndrome being found in relations to nature, inside the human self, at the micro-level of the family, the meso-level of society and the macrolevel of the world society, for instance in inter-nation relations.

A number of factors are explored for their contribution to this situation, such as economism, secularization, human rights, literacy, health, Roman Law, etc. But no single factor is held responsible for such comprehensive changes. Epistemological atomism would probably itself be a major contributing factor.

If it is in the weakening of structures and cultures that the source of so much violence and social disintegration today can be found, then it is in social development, meaning (re)structuration and (re)culturation that remedies have to be found. Some examples of rehumanization are given. The Japanese social construction is seen in this perspective as still holding out against Westernization. Many, many more are needed. The situation is serious, and rapidly wiping out advances elsewhere.

\section{THREE THESES ON SOCIAL DISINTEGRATION}

To go straight to the issue, the first thesis is simply: many human societies (perhaps most) are in a state of advanced social disintegration at the close of the 20th century, at the threshold of the Third millennium $\mathrm{AD}$. This does not mean the situation is irreparable. But it does mean that remedies have to be found and enacted quickly, partly to halt disintegration (negative social development), and partly to build more solid societies, not only integrated but less susceptible to social 
disintegration (positive social development). Such societies should also be capable of providing "human security", here interpreted as satisfying basic human needs (positive human development), or at least of reversing processes of human needs degradation (negative human development). In the same vein, they should be capable of enhancing the eco-systems, building diversity and symbiosis (positive nature development), or at least of halting processes of eco-system degradation (negative nature development). To this should be added a world dimension: if the world is a society of societies that society should also be integrated (positive world development) or processes toward disintegration should be reversed (negative world development).

Four spaces of development (Nature, Human, Society, World), and for each one a more modest negative task and a very ambitious positive task. A tall bill! In addition, these lofty goals may not even be compatible: a disintegrating society may also be more flexible, capable of meeting new challenges; and an integrated society may also be too rigid to take on, creatively, new tasks. But that all remains to be explored.

Dramatic, somewhat apocalyptic statements like the thesis above are frequently heard nowadays. They can be brushed away as more cases of drama supply to meet a perennial drama demand. Another, less reassuring interpretation, would be that there might be much truth to them. At this introductory phase of the story to be told in these pages one point should be made: a thesis about social disintegration is not in and by itself a statement about eco-crisis (depletion, pollution, overpopulation or any combination of the three), about misery, unemployment, low or negative economic growth, or violence and war. The statement is about society as something sui generis, of its own kind, as sociologists have always insisted. "Social disintegration" in addition as another problem, closely related, perhaps even more significant in its consequences than all the other global problems alluded to as nature, human and world development. And being different the problem will hardly yield to remedies designed for the old problems. New approaches are called for.

So, let us identify social disintegration as a global problem, among other global problems, distributed on the spaces of the human condition used above, adding the "space" of time, so far used mainly for ecology, and culture:

SPACE:

NATURE:

HUMAN:

SOCIETY:

WORLD:

TIME:

CULTURE:

\section{GLOBAL PROBLEM:}

ecological degradation, population

poverty/misery, repression, spiritual alienation economic underdevelopment; social disintegration massive violence, war (inter-state/inter-nation) non-sustainability inadequacy 
The four global problems italicized above have already received general attention to the point of being the basic foci of the many endeavors by the United Nations under the headings: "environment" (for nature), "human rights", "development" (for society) and "peace" (for the world), with a time dimension added recently; "sustainability". Although nobody is in favor of non-sustainable solutions to the problems of environment, human rights, development and peace this is a useful reminder of the importance of solutions being reproducible, if possible even self-reproducible (as opposed to stop-gap measures or measures that consume more problem-solving resources than they produce).

The other three problems on the list above have not entered the general discourse, yet. There are reasons for that. The specialists on "spiritual alienation" would be religionists and psychologists, on social disintegration social scientists in general and sociologists in particular, and on the possible inadequacy of mainstream (meaning Western) culture, religionists again, cultural anthropologists, philosophers. In other words, new expertise, so far mainly limited to UNESCO meetings. They do not carry the same weight as the natural sciences, economics, and security studies assumed adequate for the problems discussed.

The three additional problems are also found in the core of the dominant social formation, in and of the West, questioning individual internalization, social institutionalization, and the culture. Lives lived without meaning, societies disintegrating, cultures without answers, are serious problems sui generis; not only side-effects or side-causes of the problems of eco-breakdown, misery and war. Moreover, they are strongly related.

For the second thesis we need a simple definition formula: social = structural + cultural. By "structure" we simply refer to "patterned interaction", the macro, gross, general picture of "who relates to whom, how, when and where". This is social traffic as seen from the top of Empire State Building, not by watching drivers from the corners of Fifth Avenue and 42nd street in NYC. The key word is pattern, not the individual variations. There are no individual name tags. Human beings appear as "driver", "cop", "pedestrian". The structure changes over time. The term is inseparable from the term "process"; there may be stability, secular trends up or down, cycles (with any period, like the 24 hours and 365 days cycles in the example above).

By "culture" we mean the what and why of interaction; and the what not/why not important in explaining missing interaction; the structure not there, the absent link of interaction. Whereas interaction is between actors (and patterned interaction is the mega-version of the single interact); culture is within actors. But it may be shared: patterned culture is 
the mega-version of the individual why and why not; the mutual rights and obligations of interaction, the expectations, on binding normative culture.

The second thesis can now be formulated: at the roots of social disintegration is a twin process of destructuration and deculturation, heading for structurelessness and culturelessness. Following Durkheim we shall refer to culturelessness as anomie; and then introduce a neologism for structurelessness, atomie. Of course we have not come that far. Society is not yet a heap of mutually isolated social atoms, individuals; and there is still much binding normative culture around. But we may be on the way.

To where, to what? To a society of Leibniz' monads, fully selfsufficient? Obviously not, for human individuals can hardly survive in total isolation. But we can easily imagine inter-action reduced to a thin minimum, like some e-mail contact; making society a set of isolates more than a structure relating positions filled with individuals. In other words, the actor would be the isolated individual as such, not the individual as, for instance, pater familias, as "head" of the family, as CEO ("Chief Executive Officer") or SEO ("State Executive Officer", the head of state/government). And the normative culture informing these individuals about what to do would be centered on that which serves the individual. No interacts, only acts.

In short: at the end of the road winding through history and into the future we see a social formation ("society" may no longer be the term) basically atomized into individuals, thinly and weakly related, each acting out of egocentric cost-benefit. We are close to this state of atomie, but there is still some interaction left. We are also close to anomie, where the only binding normative culture left would be individualized costbenefit analysis. Anarchy would be another term, bellum omnium contra omnes, homo homini lupus. The social fabric (le tissu, el tejido), the social body, lo social, falls apart.

The third thesis might read something like this: we are at a stage in human history where the problem is not only whether interaction structures between individuals, groups and countries are right or wrong, but whether there is any structure at all; and not only whether the culture defining right or wrong is right or wrong, but whether there is any normative culture at all.

On the road we would expect a number of social phenomena.

First, we would expect the focus of interaction to shift from "mutual rights and obligations", a reciprocal mix of egoistic and altruistic 
orientation, to an egoistic orientation of "what is in it for me". For organization members the shift is from reciprocity to "what can the organization do for me". Like predators they descend upon macroorganizations like State and Capital, preying on them for individual benefit, then withdrawing with the booty. Meso-organizations, like NGOs including parties, trade unions, churches, are used as stepping stones. Micro-organizations like families and friends are not spared. Spouses will demand services like sex and security, and in addition "freedom" (particularly husbands). The offspring sees the family as a launching platform in life and offer little or nothing in return after, and even before, take-off.

Second, we would expect increasing corruption at all levels of social organization. By "corruption" we mean a way of using organizations for egoistic purposes, influencing decisions by injecting resources (money, sex) into the process; corruptor or corruptee acting out of egoistic costbenefit analyses.

Third, with social nets, organizations, decreasing in significance and the social knots, the individuals, on the increase, we would expect increasing mobility out of nets, relations and organizations; indicating that they have been used. After exit there may be entry into new ones, or into individual monads. People will vacate bonds between spouses, parents and children, siblings, friends, neighbors and colleagues, frequently and easily. New relations may become increasingly thin, shallow.

Fourth, we would expect increasing violence at all levels of social organization. There would be no absolute, binding norms standing in the way, no homo res sacra hominibus. Other human beings inside the organizations will be seen as substitutable, the relationship being so thin anyhow, hence as expendable. Outside the organizations they will be seen as resources. The utility supposedly accruing from violent acts will be weighed against the disutility of punishment, and the probability of detection/punishment. As violence becomes pandemic the latter probability will tend to zero given the asymmetry between the ease of committing a crime and the difficulty of detecting it.

Fifth, we would expect increasing mental disorder, assuming that human beings are not made for high levels of atomie/anomie but for interactive human togetherness, guided by mutual rights and obligations, in thin and thick human relations, definitely including the latter. Conduct indicative of mental disorders, such as drug consumption, alcoholism, sexoholic and workaholic behavior, perverse physical and verbal violence, are also efforts to find identity in tighter and thicker human interaction, and in the deeper recesses of the Self. They are outer and inner journeys. 
When such efforts fail suicide is a possible way out; not only out of despair, but also as the ultimate act of egoism.

Summarizing, this is a fairly bleak, some would say far too dark image of human society today. But the problem right now is to understand these processes in order to arrive at some idea of where we are right now; ou en sommes-nous. For that we need some kind of macrohistorical perspective, with all the shortcomings of abstracting and generalizing from a super-complex reality.

\section{A MACRO-HISTORICAL PERSPECTIVE: STRUCTURAL TRANSFORMATIONS}

Imagine we now divide human history in four phases, calling them "primitive", "traditional", "modern" and, then, "post-modern". In other words, "modernity" is not seen as the end of history, and certainly not as global market economy cum democratic polity; a social formation seen here as highly unstable. A fourth phase is added, the phase that comes after modernity, like the "middle ages" come between antiquity and modernity, and "metaphysics" comes above or after physics. The post-modern phase. The term is frequently used; the following is an effort to give that term a richer connotation.

"Primitive" will be identified with mobile hunter-gatherers and nomadic pastoralists; "traditional" with sedentary, local agriculture and the emergence of classes and castes that do not have to engage in manual work for a living; "modern" with the large-scale organizations of State, Capital and Media, building state, regional and world bureaucracies, markets and meanings; and post-modern with the destructuration and deculturation alluded to above. The post-modern society is seen as essentially chaotic and anarchic for reasons to be given in some more detail below. In other words, it is not seen as a global version of modernity but as its antithesis, or as one of several antitheses.

The story to be told here, reduced to a brutally simplistic formula, is the story of humanity on its way from nomadism to monadism. For that social story to be told we shall proceed on the two parallel tracks above; one structural and one cultural. To do this some concepts are indispensable.

Above some references have been made to thick versus thin interactive relations. Let us now shift to primary and secondary relations, defining primary (in the Weber-Toennies-Sorokin-Parsons tradition) as "diffuse" ("thick") and particularistic, meaning relating to that 
particular Other, not to anyone of the same kind (in other words, the relation is non-substitutable). The definition of "secondary" would be based on the opposite pair: "specific" ("thin") and universalistic, meaning treating everybody of the same kind, satisfying the same (low) number of characteristics, the same way. The classical examples of primary relations would be to close relatives; the more remote (cousins fourt removed, for instance) being treated the same; and friends. And enemies. But it would also include colleagues and neighbors, work places and voluntary organizations. In short, kinship and friendship, vicinity (also community) and affinity, workship (also school) and worship. High interaction frequencies will rub off; over time small-and-thin relations will be thicker and less standardized. For all six cases some collective Self is defined, offering identity and some security in return for some altruism.

Let us then introduce another variable, so often missing in social analysis: size, the sheer number of people involved. Let us divide organizations into "small" and "big", the dividing line being roughly the upper limit to the number of people a human being can identify, and relate to, positively and negatively. The order of magnitude would be 102-103. Since primary relations are based on identification, we arrive at the simple conclusion that big-and-thick is impossible. Secondary relations will tend to be big (and vice versa); only when small can they be primary.

Thus, human interaction structures come in two basic modes: thinand-big, and thick-and-small. Let us call them Alpha, the pyramid, and Beta, the wheel. In modern societies Alpha is organized by the three pillars of society, State, Capital and Civil Society, in the form of huge bureaucracies (including armies and universities), corporations, and people organizations. But inside Alpha small, informal Beta structures of people with primary relations, such as colleagues who become friends, or enemies, would be nesting; growing in cafeterias, over repeated encounters in lifts, some evolving into super-Beta relations known as love. Seen from Alpha they all introduce personal and subjective elements in the impersonal, objective atmosphere of a perfectly constructed Alpha, with everybody substitutable, even if this means alienated. Alpha people are right: those who spy on Alpha centers for state and corporate secrets often use Beta networks, including love relations, to get access, like the classical secretary making extra photocopies for a friend.

Let us then introduce a third variable, vertical versus horizontal, here seen as relational, not only relative, as exploitative, grossly asymmetric in terms of net benefits. Why do people enter such vertical, exploitative relations? Because they may have no choice, forced by coercion or 
tradition. The alternative to exploitation may be starvation (Marx on capitalism). The result is vast action spaces for people on top, straitjackets at the bottom; material enrichment on top, impoverishment lower down. Challenges on top, routines at the bottom. In horizontal relations this is better distributed; gross asymmetries lead to break-ups in thin relations.

Alpha tends to be vertical. Layer can be added to layer, in principle covering all of humankind through processes of globalization in one big pyramid or hierarchy with a single apex. This projection of the State would be known as World Government, and the corresponding projection of Capital as the World Market. The present G7 has aspects of both. But so far alphaization is clearly more pronounced at the regional than at the world level; the European Union as seen in the Maastricht Treaty being one example (the Soviet Union was another, but State and Capital were more clearly merged into one pyramid than in the EU or the U.S.).

Beta can be both vertical and horizontal (Gamma). A tribe run by chiefs and shamans, villages run by Big Men and land-owning families, families run by a pater familias, marital relations under conditions of patriarchy (and the infrequently found matriarchies), or the small farm/ firm with very tight and very authoritarian relations under the "boss" are thick and small and also vertical. And they can be horizontal like in kinship and friendship/enmity groups, among neighbors and colleagues; with other human beings in general, in worship and workship.

Horizontal Alpha structures can also be imagined (Delta). At present electronic communication, like Internet, may serve as an example, as long as the information superhighway has a topography without centers and peripheries. Transportation superhighways tend to be rooted in big urban centers reaching into the peripheries. However, peripheries could be connected, leveling the center-periphery gradients. In the same vein, the information super-highway will probably develop even steep gradients (like toll gates); and we are back to traditional Alpha.

As pointed out repeatedly, societies, or social formations more generally, as we know them, are mixes of Alpha and Beta. The question is how strongly either one is articulated. So let us answer that question in terms of "strong" and "weak" for both, giving four combinations (Alpha/Beta is not a dichotomy):

Figure 1: Human social (trans)formations: Structural macrohistory

\begin{tabular}{|lcc|}
\hline Alpha strong & II. Traditional society & III. Modern society \\
Alpha weak & I. Primitive Society & IV. Postmodern society \\
& Beta strong & Beta weak \\
\hline
\end{tabular}


The story, as reported here, follows the double line, and starts in the bottom left corner. A humanity divided into small mobile groups, clans, lineages, small enough to be "in-groups", with primary relations dominating, essentially kinship. A tight net of mutual rights and obligations spun inside the group, possibly with negative or no relations at all toward the out-groups they would encounter on their wanderings. They, precisely they, would probably be conceived of as categories of people, not even with the differentiae specificae given to them by Alpha logic in terms of their social positions and their qualifications for being allocated to such positions. The in-group would be too small to develop layers of verticality beyond gender/generation and for that reason be well integrated socially and humanly. The weak point would be not only the thin or empty relation to other groups, but also that integration may be too tight, "suffocating".

With sedentary ways of producing for a livelihood and a higher level of agricultural productivity--one family working on the land producing enough surplus for 1.1, even 1.25 families-- the material basis was laid for the classical caste-systems:

Figure 2. Non-manual castes: Four systems.

\begin{tabular}{|lllll|}
\hline & Europe & India & China & Japan \\
\hline First & clergy & $\begin{array}{l}\text { brahmin } \\
\text { clergy }\end{array}$ & $\begin{array}{l}\text { shi'h } \\
\text { bureaucrats, intellectuals }\end{array}$ \\
\hline Second & aristocracy & $\begin{array}{l}\text { kshatriya } \\
\text { warriors }\end{array}$ & nung & \multicolumn{2}{c|}{ farmers } \\
\hline Third & merchants & vaishya & kung & ko \\
& merchants & \multicolumn{2}{c|}{ artisans } \\
\hline Fourth & workers & $\begin{array}{l}\text { shudra } \\
\text { workers }\end{array}$ & \multicolumn{2}{c|}{ shang merchants } \\
\hline Fifth & outcasts & $\begin{array}{l}\text { outcasts } \\
\text { women } \\
\text { women }\end{array}$ & $\begin{array}{l}\text { outcasts } \\
\text { women }\end{array}$ & outcasts \\
& children & children & children & children \\
\hline
\end{tabular}

The history of traditional society becomes to a large extent the history of the relative power of the upper layers in what has to be an Alpha structure, unless the unit (eg., the village) is small. One possibility is the ranking order indicated above; with the European and Indian systems being quite similar, and the Chinese and Japanese also quite similar (thus, formulas like "Indo-European" and "Sino-Japanese" apply not only to languages). Another possibility, as pointed out by Sarkar, is a circulation of castes, in the order kshatriya-brahmin-vaishya-shudra (the kshatriya enter to create order after the people have had their say, but they are culturally so primitive that the brahmins enter to restore culture, 
but they are economically so amateurish that the vaishya have to put the economy in order, but they are soexploitative that the shudra people make revolts, and so on).

At this point solid vertical distinctions between people and elites have emerged. Alpha structures, mainly local, are being articulated. Modernity brings that process further in Alpha strictu sensu: country-wide, hierarchical, with a well-defined specificity in social relations stipulated in written contracts, and a universalism opening the positions in the structure for citizens satisfying well-defined, explicit qualifiers. Diffuse, particularistic relations have to be weeded out from the Alpha garden, ultimately to look like the orderly French gardens that emerged at about the same time (not baroque!). For Beta relations, please use time after working hours, and weekends.

As Alpha becomes more dominant, Beta not only becomes recessive, but starts disintegrating. One reason is simple: individual time budgets. Alpha requires full attention, because the jobs provided by Alpha are full time jobs, and because the occupants of Alpha positions are not supposed to think Beta thoughts. Some Beta structures have to go, starting with such old work structures as extended families and traditional villages. Cities are to Alpha what villages are to Beta: liberating people from the stranglehold of very tight human relations in a village, then suspending them in the thin air of urban anonymity.

Cities provide more space for Beta structures than villages for modern Alpha structures. However, these Beta structures are decreasingly related to work and increasingly to leisure, leading to the well-known pattern in many modernized countries today: villages gradually being converted from sites of agricultural production to sites of weekend leisure, and to some primary and tertiary production, plantation and tourism, for far-away buyers.

We now have to introduce a thesis, or rather an hypothesis, important for the following: A Beta structure is natural to the point of being indispensable for human beings. Only Beta type relations cater to the whole person and give the person a sense of belongingness. This should not be confused with identity or sense of meaning of life; that can be enjoyed also in an Alpha structure, even in a non-structure (Formation IV). To belong is to have a home, somebody to relate to, somebody who knows more of the story than any bureaucracy can do. The argument is not in favor joint or nuclear families, different sex or same sex unions, with or without children. The argument favors some Beta unit, thick-and-small, with more total relations. 
Objection: if Beta is the natural structural environment, how is it possible for Alpha to expand at the expense of Beta?

Answer: because Alpha has much to offer in the short run. For those on top Alpha offers the material fruits of verticality; power, challenges. For those lower down the gains may turn into losses, but the costs of being marginalized may be still higher. The Alpha lure, you are in it!, even as a peon in the post office in a village in East Bihar, or second speed EU member, is there. For Alpha holds out a reward for good behavior unknown to Beta: upward mobility, if not for you, maybe for your offspring. In Beta there is always room for improving the relation, to become a better friend, a better neighbor. But if an attraction of Beta is precisely its horizontality, then there is no way up. Nor is there any way down. There is a way out: if you do not behave. The problems, and the attractions, in Alpha are vertical. In Beta they are horizontal: belongingness versus loneliness.

One formula often used for modern society is Alpha for production, Beta for reproduction. From Alpha the work output may be considerable. In Beta human beings are repaired, maintained, sustained.

Formation I would show high levels of stability, keeping humans intact, leaving few traces on nature as the work output is negligible and the consumption of natural resources likewise.

Formation II leaves more traces. There will be monuments to the glory of the upper castes: temples (mosques, churches) for the clergy, forts for the warriors, market places, banks etc. for the merchants; poverty for the people; all wrapped together in cities. But even if human beings are exploited and repressed, they still belong somewhere, sustained, repaired. Reproduced.

In formation III, however, production starts outstripping reproduction. The output is phenomenal. Alphas of all kinds get deeper roots and expand geographically and socially, covering ever larger territories, not only countries governed by states, but empires governed by mega-states. The production of goods/bads and (dis)services outstrips what anyone might have imagined. But Betas are disintegrating, and not only the extended family and the traditional villages. The nuclear family splits not only between husband and wife, but also between parents and children, and among siblings. Neighborhoods break down when people move geographically too frequently to sustain relations based on vicinity. Invariably the same will apply to friendship and to affinity: neither can survive the high levels of social mobility, sideward, upward, downward of modern society. Worship under the same God may still remain. About God, however, see next section. 
The transition from primitive to traditional was made possible by the agricultural revolution, growing plants and breeding cattle in a relatively sedentary, basically Beta way. The transition from traditional to modern was made possible by the industrial revolution providing the goods, the scientific revolution providing the knowledge, and the transportationcommunication revolution extending Alpha reach.

But how about the transition from modern to post-modern? As we are talking about destructuration anything removing human beings from direct interaction would count. A key word is tele. Direct interaction is multisensorial; no telecommunication so far goes beyond the auditive and visual. Interaction is till there, but it is trimmed down, stripped, more naked. As anyone talking over the telephone without watching the facial expression and the body language will know information gets lost in the process. And as anyone comparing telefax to telephone knows, the tone of voice may say more than the words. So the term "information revolution" will not be used, not for the obvious reason that what is conveyed is often disinformation, but because of the high level of deinformation when so much quality is lost. Information retrieved from an encyclopedia or CD-ROM is not the same as information conveyed by a loving parent or concerned teacher (but the two obviously do not exclude each other).

Symbolic interaction via words or other symbols, whether arriving on ordinary or information highway substitutes for direct human interaction. The term is symbolic revolution, from proclamation of edicts via modern media to automation-robotization. Alpha is there. But human relations are not.

An image: Los Angeles, 1992. Certain parts of the once magnificent city are wastelands. There are streets and buildings, even shops, even if waste is piling up all over, the buildings are derelict and the shops are barricaded. More importantly, they are all disconnected from each other, there is not even a concept of neighborhood. Nobody knows who is next door, nor do they care. People come, goods and services are peddled, they disappear. At night everything is locked up, dark, desolate.

And that is when the marauding gangs take over. They are the new nomads; the city-scape is their resource. Unable to survive in nature they know how to survive as hunter-gatherers in the urban wastelands; hunting cars, gathering their contents. They are the products of formation IV, crystallized as a new formation I, preying on the wasteland, fighting rival tribes, including a police tribe hunting and gathering gangs, LAPD. Strong Beta structures re-emerging. Ready for a second cycle?

There is a logic to this. Alpha has not disappeared, but has become 
very lean and mean, devoid of human content (thus, in Figure 1 we are talking about "weak", not "zero" Alpha). There is work output, although some quality may get lost in this dehumanization process. Much more disturbing is the question often raised by the ultimate stage of dehumanization: not only is the interaction symbolic rather than direct, but the receiver, and sometimes also the sender, is even a non-human, a robot. And robots do not crave for Beta groups, they are custom-tailored for a high Alpha life expectancy. So the disturbing question is obvious: if robots do so much better, for what purpose do we have human beings at all?

The first answer is obvious: even if robots are better at production, humans are better at consumption; in fact, the whole purpose of the exercise is to liberate human beings from dirty and dangerous, humiliating and boring work, leaving all of that to robots so that human beings can concentrate on creative and non-programmable tasks and enjoy the fruits, as consumers.

The second answer would be more reflective, taking into account that robots also have to be reproduced, sustained, with energy and spare parts inputs, perhaps also reprogramming. The total cost-benefits, even done in the most naked economistic way, may turn out to be less obvious with the destructuration bill in.

The third answer may point out that not so much is lost anyhow. With the symbolic revolution not only production can be carried out in loneliness; the same applies to consumption. There is a neat isomorphism between assembly line production, in series and bureaucratic production in parallel, on the one hand, and a magazine circulating in an office (in series), and a family consuming TV programs next to each other (in parallel) on the other. All four cases are based on action (like turning nuts in assembly lines or zapping TV at home), not on interaction.

The sum total is not only Alpha but perverted Alpha. If now the thesis of a human need for Beta as something natural is correct, we would expect Beta to be sprouting. But what kind of Beta? Alpha supplies all goods and services, leaving few opportunities for green production on the side. If Alpha is dehumanized anyhow, then why not treat it as such? To whom do you feel more attachment, to your fellow corruptor/ corruptee, perpetrator/victim, or to an abstract, symbolic structure? 
Let us summarize some of the points made:

Figure 3. Formation structural dynamics: Some basic factors.

\begin{tabular}{|l|c|c|c|c|}
\hline & Primitive & Traditional & Modern & Post-modern \\
\hline Alpha & weak & strong & strong & weak \\
\hline Beta & strong & strong & weak & weak \\
\hline Growth & low & high & high & low \\
\hline Exploitation & low & high & high & low \\
\hline Alienation & low & low & high & high \\
\hline
\end{tabular}

Why do human beings engage in such exercises? Because the grass is greener on the other side. We seem to be fascinated with what is missing, and take what we have for granted; assuming it will remain there forever and not be eroded by the relentless search for the new. Till we end with a very bad deal, indeed.

Of course Primitive Man becomes fascinated with the growth, and with the glory, produced by traditional society. So, as Ibn Khaldun points out, the desert tribes knock down the gates and storm the city, sharing in the power and the glory, ultimately running it down for lack of asabiyah, solidarity (a premonition of the theory underlying the present paper). And in the same vein Traditional Man becomes fascinated with the tremendous growth and power, with the national, regional and global reach achieved by Modern society. He no longer knocks down any gates, but he joins as a humble immigrant, at the margin of the host country Alpha structures, contributing to destructuration both places. He came from reproduction without production and enters production without reproduction. He participates in building The Wealth of Nations, at the expense of The Moral Sentiments; the point-counterpoint in Adam Smith's brilliant reflections.

\section{A MACRO-HISTORICAL PERSPECTIVE: CULTURAL TRANSFORMATIONS}

Let us now try the same story from a cultural point of view, focussing on binding normative culture, and particularly on the source of normative culture, religion and such secular successors as national-ism, state-ism, capital-ism, science-ism. Religion contrasts the sacred and the secular; the awe-inspiring, that which cannot be touched, and the ordinary, the profane. In many religions there is also a third category: the evil, to be feared, to be avoided, and if possible, destroyed. Obviously, people are not born with, but into a religion. There may be a basis in the physiology 
of the brain (and elsewhere). But details are learnt.

But what would correspond to Alpha and Beta? There is the theological distinction between the sacred as immanent, inside human beings and nature, and as transcendent, in a God residing outside the planet, above. That god may be a Mother god (like in Japan) or a Father god, but in the Occident (as defined by the abrahamitic religions, JudaismChristianity-Islam) this takes the form of Father-Sky, the Father in the Sky. The opposite would be Mother-Earth; the Earth that gives birth to our livelihood, the Earth that nourishes us, and ultimately receives us upon death.

Immanent religion is more horizontal, transcendent religion more vertical. But rather than dividing religions in immanent and transcendent it might be more fruitful to talk about immanent and transcendent aspects of religions. In the three occidental religions the transcendent aspect is dominant; in addition there is Evil, presided over by Satan. Prayer and submission to God are the adequate approaches. In immanent religions meditation in Self and compassion with Other may play similar roles.

However, immanent religion has a dark side, tending to be particularist rather than universalist. The sacred nature of Other may apply to the in-group only, not to the out-group. The message of transcendent religions like Christianity and Islam (but not Judaism and Shinto) would be that you are all in it, all protected from above. The condition is that you submit and pray.

Figure 4. Human social (trans)formations: Cultural macrohistory.

\begin{tabular}{|lcc|}
\hline Transcendent strong submission & II. Traditional society & III. Modern society \\
Transcendent weak & I.Primitive society & IV. Postmodern society \\
& Immanent strong compassion & Immanent weak \\
\hline
\end{tabular}

The story, then, would run approximately as follows.

Primitive society would be protected by strong ingroup norms, being tight and cooperative. Outgroups may prove friendly but also may not; so any notion of the sacred would not a priori extend to Other. They would have to prove themselves, not by submitting to the same FatherSky, but by relating cooperatively. They become human by being accepted parts of the social network, not by any abstract human-ness (that is probably Occidental).

Traditional society might also need some transcendent deities particularly protective of the upper layers of society and more accessible by them than by common people. Religious relations have to mirror social relations. But the social unit is still small. Transcendence and immanence can be combined. 
Modern society is almost inconceivable without transcendent religion; sacred or secular; a deus in the rex gratia dei. There has to be an authority beyond the apex of the Alpha pyramid as there is so much power to legitimize. Father-Sky supplies the authority, not Mother-Earth, she is to close to everybody. And just as imperialism established the first global super-Alphas, imperial rule and trade companies, missionarism established the homologue supremacy of universal, transcendent religion. This holds for Islamic as well as for Christian imperialism.

Immanent religion was considered pagan and particularistic, standing in the way of a universal god in need of (more than willing) missionaries and colonizers to bring the message. Imperialism and transcendent religion came hand-in-hand, one as the condition for the other. Indigenous Beta and immanent religion could then be eliminated together, as pagan, archaic.

Objection: how about the Enlightenment, and secularism in general; does this picture not paint the Occident too religious?

Answer: Islamic colonialism/missionarism started right after the inception of Islam $(+622)$ and had the foundation of the Sultanate of Delhi in +1192 as one crowning achievement. From there it went eastward, stopping so far at the southern end of the Philippines. Christian imperialism (if we disregard the Roman Empire which was not Christian in its expansionist period) started for real in the 1490s, westward (Columbus) and eastward (Vasco da Gama). The pattern was set under religious auspices.Enlightenment came to Christianity much later; to Islam (perhaps) not yet. Needed was a universal, overarching God/ Allah whose commands would be binding on all believing imperial subjects.

Enlightenment and secularization (in the West) set in somewhere on the transition from Formation II to Formation III. The functions fulfilled by universalist/singularist religions with Chosen Peoples still had to be fulfilled, and universally valid science claiming to represent the only possible truth with the scientists of various kinds as the Chosen People met the bill. Alpha construction could now be made in the name of the three modernizations carried by state logic, capital logic and scientific logic; as substitutes for religion (with Ratio, rationality, as the overriding theme). The project is still on, now under the heading of "development assistance".

But what happened to the Church as the Alpha prototype? The role as representative on earth of the omni-present, omniscient and omnipotent causa sua God, went to the three pillars of power in modern society: State, Capital and the Media; the carriers of state logic, capital logic and reality representation of modern society. Underlying that a new 
ethos took shape, nationalism, providing large parts of the world with national statism, national capitalism and national media, with the disequilibria this leads to when the territories covered by state jurisdiction, capital penetration and national settlements do not coincide.

Of course, to some extent posited against State and Capital is Civil Society, with a contract (rule of law/democracy/human rights) with the State and, and no contract, only a market place with Capital and Media. And new priesthoods emerged as carriers of the new faiths: jurists for the State, for Capital the economists, for Media the journalists, for Civil Society political ideologists and for the Nations the nationalists.

In short, the structure of the transcendent God, chosen by Him as the Chosen People and chosen by people as object of worship remained intact. The places of worship were different, the content of the prayers varied, but the submissiveness stayed. For top positions in Alpha new faiths were needed, such as allegiance to the new priesthoods, meaning concretely faith in the human Ratio and such products as jurisprudence and mainstreameconomics. In addition comes faith in the (virtual) reality images produced by the Media, and in nationalism. Modern society has been laboring under such formulas for some centuries by now.

Thus, human beings were almost deprived of immanent religion through the missionary activities of the religions of the imperial powers. But with that project still on the second project of the West, secularism started undermining transcendent religion, leaving human beings deprived of Father-Sky, with no Mother-Earth as alternative, and only small groups (Quakers, Buddhists) still insisting on the sacred nature of life, particularly human life. And this is exactly Formation IV, for secularism, in the shape of humanist ethics, has not been capable of producing binding norms for human behavior. Why shall you not commit adultery, kill, steal and lie when other humans are mere objects and there is no accountability to higher forces as there is no transcendent God anyhow?

The final result is the total anomie of Formation IV, with human beings left with the only normative guidance that always survives: egocentric cost-benefit analysis. The point is not normlessness, the point is that they are not binding; that is the meaning of culturelessness. The process has gone quite far.

\section{ATOMIE AND ANOMIE IN DOMESTIC SOCIETY: SOME IMPLICATIONS}

In Figures 1 and 4 two processes have been indicated, through four social formations. How far concrete societies, groups or individuals have 
come along these trajectories can only be decided through empirical studies. But one interesting point emerges: the more modernized society, the further advanced along this trajectory, since by "modernization" we mean precisely the triumph of Alpha over Beta as dominant social formation, and the triumph of Ratio over the Sacred as dominant moral guidance. What was not taken into consideration was that human beings may need both Beta for their personal sustenance, and the sacred for life to have a meaning and their action to be guided. Alpha alone, and Ratio alone, have provided us with material abundance and impressive control and coordination structures (in need of the counterforces generated by Civil Society, though, with the Media oscillating in their loyalties to State, Capital and Civil Society). But deep sustenance and guidance they cannot offer.

Then two things went wrong, both basically unintended. Together they catapult us into Formation IV, atomie cum anomie.

First, Alpha became more and more naked, stripped of human content as Ratio provided Alpha with its many gadgets. Take only one example: automated telephone systems, not only bypassing the switchboard lady through direct dialing, but then landing the call with "if you want, push 1", some canned music, and finally a recorded response. Whether done do save labor expenses (and time), to standardize responses, or to save the recipient from any further argument, the net result is destructuration as there is no (or very little) direct human interaction involved.

Second, the hope must have been that Ratio, seen by the great Western philosophers as essentially universal, would provide a basis for a binding ethic. The problem is not that Ratio may be less universal and more a product of the general code of the many human cultures, but that Ratio does not generate sufficient ethical commitment.

At this point the synergy between the two trajectories heading for atomie and for anomie set is. Alpha, in the shape of a modern educational system, is very good at schooling people in the products of Ratio, at the level of primary, secondary and tertiary education. The two not only fit each other by being standardized up to the country and regional levels, or the levels of the nation and the super-nation (an example of the latter would be the European Union); they are designed for each other.

But binding norms seem to become rooted in human beings through Beta, through G. H. Mead's significant Others, maybe particularly the mother. If now Betas crumble all over the place, down to the nuclear family, even to the mother-child bond, leaving more and more of the raising of children not even to the school where the single class still may have some Beta character, but to the media, parking the children in 
front of the TV/Video, then it would be a miracle if binding and positive norms should become internalized. Adding to this the well-known content of the media the general picture becomes even worse.

At least for the "advanced countries" one reasonable hypothesis would be that there is a certain synchrony between the processes of destructuration and deculturation. For other countries there may be important asynchronies to explore.

King Midas surrounded by gold, his dream, but that is also all he has? Not quite that far, yet. But we would expect a general sense of pessimism to ensure from this. And that is exactly the general finding that emerged from a major comparative 10-nation study Images of the World in the Year 2000: the more economically advanced the country, the more pessimistic in general terms the inhabitants. A premonition?

Of course, with Betas crumbling all around them they may easily become very lonely. Add to this the alienation at all levels of Alpha due to the strong rules of substitutability, and the exploitation lower down, and the lack of any other moral guidance than individual cost-benefit analysis, how would we expect people to react?

Basically the way indicated by the five theses in the introduction. But they already presuppose a weakening of Alpha, not only the alienation and exploitation/repression of Formations II and III. Under the conditions of modern society as such (not yet post-modern) people might react to Alpha as such. And if we assume those on top basically to be content, wanting to hang on, then the reaction will mainly come from people lower down.

Two formulas: revolt and apathy, boiling and freezing. Whochooses what, both or neither is an interesting problem of social psychology. From a more sociological point of view these are mass phenomena and solid indicators of malfunctioning, in no way saying that revolts may not be justified. However, if there is something humankind should have learnt during the twentieth century then it would be this: a revolution substituting one Alpha for the other, changing priesthood, may not change much.

But political violence, today referred to as "terrorism", may be a problem of structures/cultures partly of the past. Today the problem may be no structure/culture at all, and violence, hurting and harming, erupting all over as a consequence of social disorganization. Here is a typology with eight types of violence:

- Violence against Nature (ecological crimes)

- Violence against Self (alcohol/drugs/tobacco, stress, suicide)

- Violence against Family (child abuse, physical/verbal violence) 
- Violence against Individuals (robbery, assault, rape, homicide)

- Violence against Organizations (corruption)

- Violence against Groups (inter-class, inter-nation violence)

- Violence against Societies (inter-state violence)

- Violence against other Worlds (inter-planetary)

Types 3, 4 and 5 are today referred to as crimes, and types 6 and 7 as wars (for a peace researcher they are all violence). The arenas differ from one type to the other: all over Nature (like in the rain forests), at home, on the streets, in the offices, within a country (internal wars), within the world (external wars), between worlds (so far only as science fiction). But the net result is the same: life is being caused to suffer, to be hurt and harmed and traumatized, even to cease.

All over the world the same: people in shock after reading, listening to, viewing, the media. The world seems to be coming apart. Each nation wanting its state. Weapons of all kinds available everywhere. Big blocs taking shape at the world level: Rich countries against Poor as much as or more than ever; the Rich in North America, Western Europe and East Asia pitted against each other; new military alliances; culture and particularly religion coming up against secularized elites only capable of uttering the standard curse "fundamentalism". Homo homini lupus, bellum omnium contra omnes; everybody for himself; apparently out of control, unrestrained. Disintegration.

One common reflection today is that violence has become more domestic, less global, world-wide. In terms of the above typology that mans more violence of types 1-6 (but type 1 is also global!) and less of type 7. Maybe too early to judge; the data indicate constancy rather than decline in the level of inter-country violence. There is a perception of decreased threat of a nuclearEast-West holocaust in Europe; possibly due to an over-estimation of that danger during the Cold War and an under-estimation of that danger within the Catholic-Protestant/LatinGermanic vs. Orthodox/Slav vs. Muslim/Turkish triangle taking shape in Europe. At any rate, with that danger removed the world system to many (in the Northern part of the world) looks rather peaceful. But not domestic society, with nations pitted against each other all over and types 1-5 apparently on the increase in most societies.

The hope of people working for peace has for a long time been to have the world system catch up with the best social systems in controlling violence, for instance by establishing a binding rule-of-law system. The problem, as usually pointed out, is that such rules are not easily internalized in an anarchic system with everybody (meaning the states) out for themselves and nobody really can function as a Significant Other, 
a nursing mother. And they are not easily institutionalized either. There are mutual rights and obligations. But if A's right becomes B's obligation and there is no reciprocity the mechanisms for handling the conflict (the World Court, the Security Council) are imperfect to say the least. Neither rewards, nor punishment (positive and negative sanctions) are impressive. What then happens is often hierarchic intervention by big powers.

People may develop all kinds of Beta, not to mention Alpha structures across borders, but the inter-state structures are thin (this is where anarchy enters) and vertical (this is where hierarchy enters). Is the structure also big? With 184 members of the United Nations and 184 ambassadors the structure is not larger than what many individuals can handle, fitting nicely into their lists of addresses and telephone numbers. Being thin and vertical it could easily become Alpha by adding more members (such as NGOs, or direct relations to the many nations of the world). But it could not easily become Beta. In that case it would rather be Gamma, with the permanent Security Council members in loco parentis of that extended family. Feudal and paternalistic, in other words, and even so the webs of interaction will have to be spun much more densely.

The basic point here, however, is that far from the world system catching up with the better cases of the social systems, it is the other way round: the social systems are "catching down" with the world system. Read this way Formation IV, replete with atomie and anomie, is a rather adequate image of world society: vertical, with symbolic, abstract relations rather than direct interaction, short on binding norms and altruistic orientation and long on egoistic cost-benefit orientation. There are some Beta structures, like among the Nordic, the European Union and the ASEAN countries, at the world system level, like in social systems. But the Formation IV structure is very evident. And the consequence is obvious: instead of peaceful conflict solution efforts violence is used, respecting neither common values, nor any inner voice of conscience, nor the threat of punishment.

\section{FROM NOMADISM TO MONADISM: SOME FORCES MOTRICES}

The following is not a theory to account for this rather gigantic change in the human condition. Rather than a macro-history it is simply a catalogue of twelve factors often mentioned in this connection, an annotated list so to speak, even alphabetized to make its atheoretical character even more obvious (if not necessarily acceptable to the reader). 


\section{Capitalism}

The reason why capitalism tends to become not only Alpha but Super-Alpha in its basic structure, even if much is happening within, is the verticality of power that follows when high quality production factors (nature, labor, capital, technology and management) are monetized, marketed, and mobile. As they have to be put together for production, they tend to flow together or at least to be controlled together, from a Center.

The Center uses high quality factors for high quality products, in exchange for lower quality factors and products from the Periphery. Capital is supposed to beget more capital, either directly in the finance economy (speculation), or indirectly when invested in production factors used to produce goods and services in the real economy (production). Much begets more which does not mean that little begets less; the cake may expand, but then often at the expense of the external proletariat, nature, and/or future generations. New about capitalism was not that the economy had a peaked structure. What was new was the mobility, not only into the Center by investing some initial capital, much hard work, saving, greed and inconsideration, but also out of the Center through bankruptcy or lack of dynamism. The result was an anti-feudal revolution. For the continuation, see Socialism.

\section{Democracy}

Of course elections are one way of ensuring not only rule by the consent of the ruled, but also nonviolent transition from one set of rulers to the next, if they respect the secret ballot. The problem is the Alpha nature of that type of democracy; a relation between a Center of contending Rulers, and a Periphery of the Ruled, turning the pyramid upside-down once every four years (or so). This Alpha shape of modern democracy, Democracy II, differs from with the Beta shape of a more primordial Democracy I: a group (a small company, a small community or a neighborhood, a family or a group of friends, the elders in a tribe) dialoguing over issues till consensus is obtained. The relation is horizontal, everybody can address everyody's concern, the outcome is unknown in advance, there is neither winner, nor loser; in good dialogues only winners.

\section{Differentiation}

Another term is "division of labor", in a long social philosophy tradition (Adam Smith, Herbert Spencer, Emile Durkheim, Ferdinand Toennies, Max Weber) seen as a basic condition for social progress and economic 
growth in particular. The total human activity called Work is not only subdivided into tasks and subtasks, but new tasks are continuously created. As in production of goods and services so also in the production of knowledge: undifferentiated Philosophy is subdivided intodisciplines and sub-disciplines that in addition are hyphenated into cross-disciplines. The structure of the sets of Tasks and disciplines is highly complex, but the general idea is differentiation, and with it fragmentation, atomization of the individuals having these tasks and disciplines as their job. As book, Limits to Differentiation, is crying to be written.

\section{Economic Growth}

The process is almost inconceivable without a culture accommodating not only hard work and saving, but also greed and inconsideration. Systems may differ as to whether the pressure is put on the internal or external proletariats; on nature, self or the future. But something has to be moved, or transformed, or both (see Capitalism), and in the process organic relations of people to others or raw materials to surrounding nature, will be cut or at least transformed. The open wounds in quarries and mines have their counterparts in the open wounds in souls detached from each other through excessive mobility and transformation. Inconsideration means insensitivity to wounds in Self, Other and Nature. Beta structures break down, partly dehumanized Alpha structures are poor substitutes.

\section{Economism}

The term is interpreted here as a state of mind, not to be confused with the economy (the cycles linking Nature, Production and Consumption) or economics (the science about these cycles, today essentially a description and theory of one particular economic system, capitalism, hence a science that more properly should be called "capitalistics"). Economics, or the culture of homo economicus, can be conceived of as a syndrome:

- a focus on material/somatic satisfaction by goods and services;

- a focus on the human individual as the unit to be satisfied;

- a focus on cost-benefit analysis to guide individual choices.

The syndrome not only detaches individuals from each other by making the single individual the supreme decision-maker (egocentrism), but also detaches satisfiers (goods/services) from each other as objects to possessed and consumed one by one. Costs and benefits are then used to establish preferences.

There are severe problems with this syndrome, mind-set: 
- in practice only a limited number of satisfiers can be used, by definition excluding the externalities of economic action;

- absolute values (with infinite positive or negative utilities) will be excluded or relativized since they will overrule others;

- individual preferences are not easily reconciled collectively.

These are the costs, considerable, of the breakdown of the holism of the actors in collectivities, the holism of the object-world, and of absolute values: destructuration and deculturation. This is also built into the technique used: product-sum maximization, which becomes very unwieldy for collectivities of not harmonized actors and high numbers of satisfiers and useless for absolutes. When used, the result is even more atomization, destructuration and the deculturation implicit in rejecting absolute values. Thus, economism becomes the ultimate consequence of Roman Law.

\section{Gender}

Just to pick up one factor, how the genders seem to differ in their preference for alpha (male) and beta (female) and no (male) structures, assuming that women prefer to relate and network, neither to be isolated in loneliness, nor to be isokated at the top of a hierarchy. Thus, a major force behind the drive toward alphaization, and then toward monadism, from Formation I to II, II to III and on to IV, would be patriarchy: the lading structure is the structure of the leading class. And that should also apply to culture: male preference for deductive thinking and sumbission to first principle is compatible with a transcendent God; less compatible with immanence. But that also opens for a major therapy: parity instead of patriarchy, provided women have not become clones of men in the process.

\section{Globalization}

If this terms stands for global mobility of production factors and products, with more standardization of structures and cultures, then the consequence is to speed up the transition into Formations III/IV. Larger domains for structures and cultural meanings imply thinner scopes, and more reliance on least common denominators, with structural and cultural specifics receding into the background. Given the variety of idioms around the world Super-super-Alphas with truly global reach will be symbolic, based on mathematics, computer language, etc., or based on body language (sport as a universal idiom), and/or on concrete objects, goods, like people with no common idiom pointing and touching. "Here are no Greeks, no Jews; no women no men: we are all one in CocaCola" is reality, not a bad joke or blasphemy. 
And the same goes for structures: no cohesive Alpha has so far emerged covering 6 billion human beings except one: global television. There are two layers: one sender, billions of receivers. No horizontal interaction, they relate via the apex.

Will this structure endure? Probably not. Sooner or later it will go the way of all Alpha: small Beta groups take shape, like guerrillas they will relate, unite and revolt. The condition is their ability, underestimated by Marx, to overcome structural, cultural and geographical divides. But the global market prophets may have underestimated that in its wake will follow globalized workers trade unions and consumers movements. Proletarians (and consumers) all over the world, unite!" may have a reincarnation. Consumer sovereignty, if exercised on a truly global basis, may become a mjor force at the same time as nation-state democracies crumble under the weight of global forces beyond their control.

Actually, globalization may also run into another problemof an equally or more serious nature. Competition has kept capitalism innovative; not only the micro-competition from other firms in the same branch (BMW versus Mercedes), nor the meso-competition from another country (Germany versus the UK), but the macro-competition from other civilization with other capitalisms (Buddhist-Confucian versus JudeoChristian). Globalization will keep the micro and meso challenges but may strive to iron out the macro differences through homogenization into a global business culture. This means a severe reduction of the Toynbee factor of challenge followed by the creative response that presumably keeps minorities in power. And Alpha is, by the very definition built into its pyramidal shape, run by a small minority (relative to the other layers) in need of constant renewal of personnel and ideas. Globalization means mono-culture, less diversity, less symbiosis, less resilience.

\section{Health}

The concern for health fits into the general picture of secularization on two important ways: as focus on the body rather than on the state of the mind and the spirit, and the translation of eternal life/salvation as high life expectancy. Of course modern man enjoys lower morbidity and mortality. But there are no gains without some price to be paid, and the price is in the cultural rather than structural sector. Could it be that the healthy body is less able to share the suffering of others at the same time as health, one's own and that of others, is taken for granted, being no source of shared joy either? That health leads neither to a culture of compassion, nor a culture of submission follows its wake, but a culture of egocentrism? 


\section{Human Rights}

In principle human rights protect exposed individuals, emphasizing the privacy of the individual human body, of the individual human soul/ mind/spirit, and the equality of all categories of humans relative to the law. Human rights soften relations between the Center (the state) and a Periphery of individualized citizens, which is good; but also emphasize reliance on a protective, soft Center rather than human reliance on each other. An ethics of Alpha submission rather than Beta compassion, designed to soften (not weaken) the strong Alphas of Formation II and III, in ways paving the way to Formation IV.

\section{Industrialization}

No doubt this was a major factor in the transition from Formation II to III, and lead to well known problems of vertical division of labor (exploitation) within the company between employers and employees, within the country between raw material and industrial goods producing district and between countries also according to the degrees of processing. The organization at all three levels was Alpha, with a plethora of Beta groups flourishing at all levels, from boys' clubs of employers to workers' collectivities (not the same as Alpha type trade unions) controlling the level of commitment to the firm. So industrialization has been accompanied by anti-Alpha revolts of all kinds, from sabotage, go-slow, company strikes via general strikes to anti-colonial and antineocolonial movements. The struggle is still on. But the focus here is more on robotized, automated, symbolic interaction pattern with industrialization, if that is still the word. From that destructured and decultured perspective Labor and Third World struggles look almost utopian; people still relate to each other; they are not yet postmodern.

\section{Literacy}

Literacy can only be understood in terms of it alternatives: oralacy on one hand, and picturacy on the other. Oralacy has as a necessary condition memory, stored in the brain. Does it not stand to reason that what has to be memorized often is more easily remembered, recalled, related to others in Beta type relations (rather than the Alpha type relation of readers to authors), and for that reason may be more compelling? The decalogue can be retrieved from books and computers. But does that have the same binding quality as moral commands committed to the individual memory? If not, is literacy, however precious, not also paving the way from Formation II into nos. III and IV? 
Picturacy (TV, video) in principle mirrors reality and in practice constitutes a virtual reality, an as if (als ob, commesi) reality. The choice has been made for the viewer, as subjectively as any choice. Synchronic perception complements the diachrony of oralacy and literacy, but is also more easily confused with reality "out there". This, then, adds to the detachment by dehumanized structures and relativized cultures.

\section{Migration}

Whatever the reason, migration as massive mobility across borders, which often also means across cultures, will speed up transitions to Formation IV considerably, even to the new Formation I of the Los Angeles metaphor. Thus, a person, with or without friends and family, detached from the structures of the country of origin, arrives in the host country, presumably with his/her culture more or less intact. There has to be some attachment to a new Alpha structure, relating to the new State (permits, etc.), the new Capital (job, etc.), and may b also some footholds in the new Civil Society.

However, the cultural idiom being new relations will be thin indeed. The host culture is not easily internalized. A likely result is a tightly spun Beta group of immigrants suspected of being predators rather than prey (or, often, both). Los Angeles. This should not be confused with colonialist transfers of total societies, with the host population marginalized or exterminated.

\section{Poverty}

Of course poverty is important as a problem of all formations, when instead of looking at structures and cultures we focus on basic human needs and their satisfaction. But from a structural point of view poverty must not lead to atomie, it could also lead to tightly woven Beta groups fighting poverty together. And it does not have to lead to anomie, it could also lead to the famous culture of poverty of the favela, etc., which may sustain rather than negate poverty, but also make it more bearable. The worst poverty would be needs-deprivation combined with atomie and anomie, in other words the poverty of Formation IV. And this may very well be the condition under which Los Angeles is no longer a metaphor, but a world reality.

Another, updated perspective on poverty might bring in the jobless growth characteristic of the present world economy. The distinction between employed and unemployed is too sharp, however. More typical is perhaps not only underemployment but underpayment in the sense that the concept of the breadwinner able to feed a whole family, one 
job-one family, is disappearing. In principle this should force a number of people, in a family or other kiship units, or in a neighborhood, a commune, to join their incomes so that all can live from it, thereby fostering beta restructuration and solidarity.

\section{Roman Law}

It was all pre-programmed in Roman Law if the following reading of that law or basic philosophy is accepted. In what we generally assume to be true about primitive societies holism figures as a basic figure of thought, both for Humans and for Nature, although in practice this applies mainly to the near-Humans, meaning the in-group, and the near-Nature, meaning this side of the horizon, which for a nomadic people is considerable. This is very far from a basic figure of thought in Roman Law, dominio, individual ownership. The ownership or use concept of primitive peoples is a coupling of two holisms: we as a group use, with care, what we find in Nature. To go or jump from that figure of thought to the Roman holisms must yield to atomism. Humans must be subdivided into persons capable of ownership, an example being the pater familias, another the emperor; and Nature subdivided into entities capable of being owned, as land, plots and minerals, plants, animals, slaves/women/ children. Obviously, for this a census, the sciences of geometry, geology, botany and zoology gradually had to take shape. But once the subdivision was done on both sides of the Humans-Nature divide, with the holisms broken, the totality could be sewn together again, the Roman (to become the Western) way: through a one-one mapping of juridical persons on objects, the dominio. What belonged toeverybody would then belong to nobody; res communis, res nullius. For the non-Western world ownership was acquired by the "first, come, first see, first own" principle: through "discoveries". There were transition formulas: the Emperor is the only juridical person, like the pater familias for the family, assuming dominio of everything- in the West scorned as "Oriental despotism".

\section{Socialism}

We know it in its stalinist and post-stalinist configuration as superAlpha, with, say, 400 people planning for 400 million in Eastern Europe and the Soviet Union (about the same structure as regional television). Means of production were collectivized, but not at the level of communes as commune-ism but at the level of the state, as state-ism (etatism). Revolts were inevitable, not only because of the brutality and repression of (post-)stalinist countries. Planning made people passive, expropriating from them not only the right to plan their own production, but even to plan their own consumption and economy of their own household, 
restricting the range of what was available. Then people demanded their right to be subjects of their own economic fate. For the continuation, see Capitalism.

\section{Urbanization}

The city is a giant Alpha administratively and often also economically, but also better suited as a host of countless, rich, diverse, shifting and symbiotic Betas than any other human habitat, if for no other reason simply because it combines size and proximity into propinquity. It has other problems, such as slum-formation, and the alienation of those who are marginalized. The young, the old and women are often excluded from the rich Beta variety of bars and clubs. Moreover, modern cities are better designed for cars than for people, eliminating many good meeting places such as parks, open land, old buildings. Like industrialization, urbanization played a key role on the way from Formation II to Formation III. But these are the problems of yesteryear even if very dramatic in many places. The problem now and in the future is that the solutions to these problems should not carry the stamp of Formation IV.

\section{TWO THESES ON SOCIAL DEVELOPMENT}

No surprises for the reader in these two theses on social development, as the antedote to social disintegration:

The first thesis reads: Create strong Alpha and strong Beta structures; to promote structuration and reverse destructuration

The second thesis reads: Promote immanent and transcendent religion; to promote culturation and to reverse deculturation

If enacted this would place us in Formation II which is referred to as "traditional society", referring to that cycle of human history. But the definitions of these formations transcend the concreteness of the travel from nomadism to monadism. We also have a future, and the hunch derived from these deliberations is that we need both Alpha (because "some big is necessary") and Beta (because "small is beautiful"). But this in no way means moving backward in history (which would be impossible anyhow), but to try to create a new cycle. A not very promising beginning has already been indicated, not only the tribal warfare in the wastelands of Los Angeles, but also the warfare in Ulster, ex-Yugoslavia, ex-Soviet Union and Turkey in Europe; Rwanda, Somalia, Liberia and Sierra Leone in Africa; Guatemala and Mexico in Latin America; 
Burma, Indonesia and Cambodia in Asia, to give some examples. Strong on Beta, weak on Alpha, and very violent.

One still positive example of Formation II comes to the mind: Japan. Betas in the form of cohorts are incorporated into the Alphas of bureaucracies and corporations by way of lifelong employment (so that people stay together inside the organization) and seniority promotion (so that people stay at the same level for some time, being promoted together at least to startwith).

But at the same time Japan also benefits from the co- existence, in one society, of both transcendent (State Shinto), immanent (Folk Shinto, Buddhism) and secularism (Confucianism). In principle a Japanese not only lives both in Alpha and in Beta, but may also pay allegiance to all three systems of faith at the same time (and in addition to that Christianity and Rationalism). Thus, we would expect a certain resilience in Japan, being both structurally and culturally intact, playing on both structures and both cultures. This might look like redundance, but the key to resilience is exactly that, redundance to be on the safe side. Hence, we would expect relatively low disintegration rates of the usual kind, adding divorce to the typology of violence.

Japan is today exposed to a tremendous pressure both from the outside, particularly from the U.S., and from the inside, maybe particularly from bureaucrats, businessmen and scholars who have been to the U.S. and found the society liberating. As mentioned above, Beta and immanent religion can be confining; Alpha and transcendent religion both open up grand vistas. But the conclusion from these deliberations would be to be very careful: the costs of that type of modernization are enormous and the remedies not very clear as moving backward, recreating past structures and cultures, may be impossible. To pressure Japan into policies that will have moves toward Formation IV as a likely consequence should be classified as some kind of social crime, structurocide cum culturocide.

Which does not mean that Japan and Japan-similar countries are perfect. With more emphasis on social growth and costs and less on economic growth and costs good policies should emerge.

In general the first thesis would have two sub-theses: to recreate Beta, and to rehumanize Alpha. One way of doing this is found all over in Western countries: create Beta inside Alphas of any kind, bureaucratic, corporate, academic. Individualismbeing so basic to Western cosmology the Japanese way of tying people to the same organization for life will almost have a taste of imprisonment, and parallel promotion would disregard differences in individual potential and merit. But Beta 
integration does not have to be cohort- (i.e., social generation) based; it could also be work-related. The problem with experiments in teamwork and team-teaching would be the scarcity of compelling indicators of the value of social integration when there are little, no or even negative economic gains. At present the significance of social integration must come as a credo.

Thus, in any trend to abolish assembly-lines in favor of teams assembling the product together there is a clear potential for Beta growth and some Alpha decline. The same applies to modern office landscapes with a high level of mutual visibility, easily organized round tasks, grouping together those who should work together. The contrast would be the one person-one office structure, an architectural recipe for fragmentation, with the lunch, the coffee-break and the water-cooler as the only alternatives. And they are not so likely to be well suited for productionoriented Betas, with the exception of the "business lunch". But what, then, happens to reproduction-oriented Betas?

At the universities this would point to the colloquium as a fine Beta structure, for professors, for students, and for both. In the U.S. these structures are remarkably infrequent.

In banking this might point to the interesting lead by the Grameen Bank introduced in Bangla Desh. Really poor people do not have equity for bank loans, if they did the loan might not have been needed. Instead ten persons guarantee one tenth each, and together they constitute a Beta group around the debtor.

This reminds us of the famous Zehnergruppen in ex-DDR, groups of ten people working together, introduced in economic organizations to increase production and productivity. As such they may have failed, as Beta groups they seem to be much missed. Of course, Western capitalist society have much to offer in terms of voluntary organizations (although they often acquire Alpha character, becoming big and formalized). But they are usually not directly work related.

Another interesting Beta innovation is, of course, what in German is called the WG, the Wohngemeinschaft, the "commune" of like-minded people living and to some extent consuming together, sharing all the work of the household. An extended family except for the kinship factor. Of course this was a longing for Beta in a society where even nuclear families collapse. It should not be judged by the ability or wish of the members to stay together as long as "real" family members; the socio-logic is different. It may also be a major way of internalizing conviviality norms.

Rehumanization of Alpha: simply ban all automated responses, let 
people have a chance to put their questions to a human being and get human answers, however fallible, back. The social costs of not doing so will by far outweigh the economic costs of employing more people in the services. Moreover, such positions do not have to be full time jobs. What is needed is humanity.

Then, some points on culture, in the narrow sense used here of binding ethical rules. In the choice between an ethics of compassion and an ethics of submission, between a religion of meditation and one of prayer the answer might be to choose both, with an important proviso to be spelt out shortly. There is much to build on; rich religious experience to draw upon. There is also room for secular approaches, perhaps not the Enlightenment cult of Ratio so much as the general wisdom of "reciprocal rights and obligations", found all over the world, with at least some ethical inspiration to be derived from its moral basis, the lex talionis, both in its negative and positive formulations.

But there is another distinction that may be more important than the sacred-secular and immanent-transcendent; hard vs. soft. The word religion comes from religare, relink, reconnect with that out there, the holy, the sacred. Union of some kind is the goal of all religions, with Others past-present-future in this life by immersing oneself fully in the net of compassion with all life, with God and others in the afterlife by submitting to His commands. In mysticism this experience probably becomes like a light so strong that everything else loses its contours.

Imagine now a circle around this epicenter of religious experience, divided into sectors for each religion. The notion of religion as linking, connecting, unifying is still there. Religion is not used to draw lines between the adherents of this or that religion, nor between the righteous and the sinners. A religion is more seen like a language, an idiom in which religious experience is expressed. This is the soft circle, perhaps more found in religions of compassion than of submission.

Outside this circle comes the circle for hard religion. The names of the sectors for the religions are the same, but the message changes character. The focus is on what divides rather than ln what unifies. Other religions are denounced as pagan, or even worse, as heresy. The sinners are in for very harsh treatment; even hell, the torture chamber of hard religion, is invoked for their afterlife. The righteous from the right religion are seen as Chosen Persons in the eyes of God, and some nations are often seen as closer to God than others, including the sinners and the non-believers. Naturally, hard religions of that type can be well suited as state religions, mirroring in religious terms the struggle among states in world politics.

So, an elaboration of the second thesis for social development would 
be to promote the softer aspects of the religions, and try to demote the harder (harsher) aspects. Thus, the most important struggle in the religioscape, the religious landscape of the world, is not the traditional struggle among religions as to which one is most suited to carry humanity forward, but he inner struggle between the unifying and the divisive forces. "Soft religionists of the world unite, you have only your harder brother and sisters to lose"? Not quite, because that would draw a too hard line between soft and hard. The important point is that the struggle is within rather than between, and that each religion has this struggle on its agenda. Moreover, the harder aspects (Inquisition, witch-burning) have no doubt contributed to giving religion a bad name. Quakers and Sufis, Buddhists and Baha' is offer much softer approaches. But none of them would be entirely free from the harder aspects.

For humanists this would imply a softening of the line they sometimes draw between themselves and the religionists, following the tradition of 18 th century Europe. In short, there is a message to everybody in the word that is No. $I$ in the vocabulary of the present Dalai Lama: compassion.

Do these two theses add up to the standard conservative message of family and Christianity? No, but that message is not rejected either. Her "family" is taken in a much broader sense, Beta. Moreover, attention is paid to how to soften, humanize, the other major structural type, Alpha. And instead of Christianity we are of course speaking about all religions, scared and secular (civil), but then limiting it again to the softer aspects. But conservatives have probably diagnosed the present situation better than many liberals/marxists/greens, by focussing on one structural and one cultural component. People on the left tend to be almost obsessively focused on some kind of Alpha, its proper design, function and structure; its distribution of rights and duties, power and privilege, at the expense of Beta (except for the greens) and culture, ethos. But however that may be, the present paper tries to give something to both, perhaps with the strong admonition to the left of taking culture, ethos, religion more seriously, getting out of the habit of seeing them as "superstructure" or "opium".

Nothing of this will emerge automatically, and in crises people may also turn to the harder aspects of the religions with divisive messages and Alpha organization. But just as we postulate a normal human Beta drive for the small an tight, why not also dare postulate a corresponding religious inclination?

And that brings us to the end of this narrative, with the short excursion into a very uncertain future. With structural and cultural ties being dissolved, we are in the, some would say absurd, situation that the most 
modern and economic/technically developed have become the socially speaking least perhaps least developed, or de-developed. Obviously, we are then not talking about the relative presence of social services (per 1,000 inhabitants, etc.) but of something held to be much more basic: structuration and culturation. Social services may be a part of the problem rather than of the solution to the extent they are operated through increasingly dehumanized Alpha structures. With atomie/anomie being the basic social price paid for modernization because people have taken for granted that society is solid and can be drawn upon for any purpose, the more and most developed have suddenly become the less and least developed.

Does that mean that the economically/technically least developed are the socially most developed? Not necessarily. Some very poor Third World countries have been ravaged by unspeakable violence between classes, nations and clans, with the rest of the world often siding with one against the other(s). Some of this violence may be attributable to atomie/anomie, and there are signs that it has reached the micro level of social organization, with family members butchering each other; i.e., total violence.

However, much is intact, in Southern and Eastern Europe more than in North-Western Europe; in Central and South America more than in North America. One day the present First world may ask the present Third world for advise about social development. If that happens, the world would have taken a major step forward. 